\title{
A quarter of a century of experience with aortic valve-sparing operations
}

\author{
Tirone E. David, MD, Christopher M. Feindel, MD, Carolyn M. David, BN, and Cedric Manlhiot, BSc
}

Objective: To examine the late outcomes of aortic valve-sparing operations to treat patients with aortic root aneurysm with and without aortic insufficiency (AI) in a cohort of patients followed up prospectively since 1988.

\begin{abstract}
Methods: A total of 371 consecutive patients had undergone aortic valve-sparing surgery (mean age, $47 \pm 15$ years; $78 \%$ men) from 1988 through 2010 . In addition to the aortic root aneurysm, 47\% had moderate or severe AI, 35.5\% had Marfan syndrome, 12.1\% had type A aortic dissection, 9.2\% had bicuspid aortic valve, $8.4 \%$ had mitral insufficiency, $16.1 \%$ had aortic arch aneurysm, and $10.2 \%$ had coronary artery disease. Reimplantation of the aortic valve was used in 296 patients and remodeling of the aortic root in 75. Cusp repair by plication of the free margin along the nodule of Arantius was used in $36.6 \%$ of patients, and reinforcement of the free margin with a double layer of fine Gore-Tex suture in $24.2 \%$. The patients were followed up prospectively with images of the aortic root for a median follow-up of $8.9 \pm 5.2$ years.
\end{abstract}

Results: A total of 4 operative and 39 late deaths occurred. Survival at 18 years was $76.8 \% \pm 4.31 \%$, lower than that for the general population matched for age and gender. Age, type A aortic dissection, impaired ventricular function, and preoperative AI were associated with increased mortality on multivariable analysis. Reoperations on the aortic valve were performed in 8 patients for recurrent AI and in 2 for infective endocarditis. Freedom from reoperation on the aortic valve at 18 years was $94.8 \% \pm 2.0 \%$. No predictors of the need for reoperation were found on multivariable analysis. Eighteen patients developed AI greater than mild. Freedom from AI greater than mild at 18 years was $78.0 \% \pm 4.8 \%$. No predictors of recurrent AI were identified on multivariable analysis.

Conclusions: Aortic valve-sparing operations continue to provide excellent clinical outcomes, although a slow but progressive deterioration of aortic valve function seems to occur during the first 2 decades of follow-up. Preoperative AI and cusp repair had no adverse effect on valve function. (J Thorac Cardiovasc Surg 2014;148:872-80)

A quarter of century has passed since aortic valve-sparing (AVS) operations were introduced in our cardiac unit. ${ }^{1,2}$ At first, we were concerned that the aortic cusps would not function normally for a prolonged period because they were placed inside a rigid root made of Dacron fabric. Also, only patients with echocardiographically normal aortic cusps were offered these operations as an alternative to aortic root replacement with a valved conduit. $^{2}$ As our confidence in AVS operations increased, we expanded their use to include patients with cusp

\footnotetext{
From the Division of Cardiovascular Surgery, Peter Munk Cardiac Centre, Toronto General Hospital and University of Toronto, Toronto, Ontario, Canada

Disclosures: Tirone E. David reports consulting work for CorMatrix and Valve Exchange and lecture fees from Medtronic, St. Jude Medical, and CorMatrix. All other authors have nothing to disclose with regard to commercial support.

Read at the 94th Annual Meeting of The American Association for Thoracic Surgery, Toronto, Ontario, Canada, April 26-30, 2014.

Received for publication March 15, 2014; revisions received March 29, 2014; accepted for publication April 2, 2014; available ahead of print June 13, 2014.

Address for reprints: Tirone E. David, MD, Division of Cardiovascular Surgery, Peter Munk Cardiac Centre, Toronto General Hospital and University of Toronto, 200 Elizabeth St, 4N453, Toronto, ON M5G 2C4, Canada (E-mail: tirone.david@ uhn.ca).

$0022-5223 / \$ 36.00$

Copyright (c) 2014 by The American Association for Thoracic Surgery

http://dx.doi.org/10.1016/j.jtcvs.2014.04.048
}

prolapse due to elongation of the free margin or stress fenestrations in the commissural areas. We believed these cusps abnormalities were caused by increased mechanical stresses resulting from dilatation of the sinotubular junction and/or aortic annulus. Thus, shortening their free margins by plication or triangular resection along the nodule of Arantius and/or reinforcement of the free margin of the cusp with a double layer of a fine Gore-Tex suture (W.L. Gore, Inc, Newark, Del), in addition to correction of the mechanism by which they became abnormal, would restore aortic valve function and expand the indications for AVS surgery. These types of cusp repair during AVS operations have had no late deleterious effects on valve function 5 to 10 years after surgery. ${ }^{3-5}$

We have proposed a classification of AVS surgery into 2 basic types: aortic valve reimplantation and remodeling of the aortic root. ${ }^{6}$ In aortic valve reimplantation, the aortic annulus, the aortic cusps, and a rim of the aortic sinuses are placed inside a tubular Dacron graft and secured below and above the aortic annulus, fixing the diameter and shape of the aortic annulus and sinotubular junction. In remodeling of the aortic root only, the aortic sinuses are replaced with an appropriate Dacron graft to re-create the normal scalloped shape of the aortic annulus, as originally 


\section{Abbreviations and Acronyms \\ $\mathrm{AI}=$ aortic insufficiency \\ $\mathrm{AVS}=$ aortic valve-sparing \\ $\mathrm{CI}=$ confidence interval \\ $\mathrm{HR}=$ hazard ratio}

described by Sarsam and Yacoub. ${ }^{7}$ If the aortic annulus were dilated, we combined AVS surgery with a reducing annuloplasty by suturing a band of Dacron fabric on the outside of the intervalvular fibrous body. ${ }^{8}$ Numerous modifications to these 2 basic procedures have been introduced. $^{9-12}$

The present report describes the clinical and echocardiographic outcomes of AVS operations at our institution during the past 2 decades.

\section{METHODS}

From May 1988 through December 2010, 371 consecutive patients with an aortic root aneurysm or ascending aortic aneurysms and aneurysmal aortic sinuses with or without aortic insufficiency (AI) underwent AVS surgery. The clinical profile of all patients and the 2 main subgroups of AVS operations are listed in Table 1. The pertinent operative data are listed in Table 2. Reimplantation of the aortic valve was performed in 296 patients and remodeling of the aortic root in 75 . During the first decade of experience, no particular criteria were in use for choosing one or the other type of AVS procedure. However, later in our experience, younger patients with inherited aortic root aneurysm underwent the reimplantation procedure exclusively, and older patients with ascending aortic aneurysm and secondarily dilated aortic sinuses underwent the remodeling procedure. We have described the technical aspects of our AVS operations in recent studies. ${ }^{10,11}$

The patients were followed up prospectively with annual echocardiographic studies during the first decade and every 2 to 3 years thereafter if the aortic valve function had remained stable. Images of the entire thoracic aorta were obtained every 5 years or more often if the patient had had dissection or residual aneurysm at surgery. For the present report, the follow-up period was closed December 31, 2013. The mean follow-up duration was $8.9 \pm 5.2$ years; 43 patients were followed up for $>15$ years but only 11 for $>20$ years. The clinical follow-up data were complete, and the echocardiographic studies were $98 \%$ complete during the most recent 3 years. The review ethic board of the University Health Network approved the study.

\section{Statistical Analysis}

Data are presented as the mean \pm standard deviation or frequencies, as appropriate. The variables and categories with low frequency are reported as descriptive statistics but were collapsed (when possible) or excluded for additional analyses. Basic comparisons between groups were performed using Fisher's exact test for all categorical variables and Student's $t$ test, assuming an unequal variance between samples (Satterthwaite methods). The freedom from time-dependent outcomes was modeled in a parametric survival model (using maximum likelihood estimates to resolve risk) that divides the risk over time in $\leq 3$ distinct phases of risk (early, constant, and late) using standard mathematical algorithms from the HAZARD procedure (available at: http://www.clevelandclinic.org/heartcenter/hazard). All associations between the freedom from outcomes and the potential predictors were first screened in univariable regression models. The associations between patient and surgical characteristics and outcomes were included in a bootstrap bagging algorithm (500 resamples). The variables with high reliability $(>50 \%$; defined as the percentage of the resample in which a given variable was selected) were then included in a multivariable parametric survival regression model, with backward selection of variables to obtain a final regression model. All risk factor analyses were performed using a unified phase of risk, given the limited number of events in some phases of risk. Life tables from the Province of Ontario from 2000 to 2002 (available at: Statistics Canada, www.statcan.gc.ca/pub/84-537-x/4064441-eng.htm) were used to estimate the 20-year survival of the patient cohort according to the age and gender distribution. Mean imputation was used to account for missing variables. All statistical analyses were performed using SAS, version 9.3 (SAS Institute, Cary NC).

\section{RESULTS \\ Perioperative Complications}

Four patients died in hospital or within 30 days of surgery. The cause of death was low cardiac output syndrome in 1 patient, acute type B aortic dissection in 1, Clostridium difficile colitis in 1 , and perioperative myocardial infarction in 1 . Thirty-four patients $(9.1 \%)$ required reopening of the chest for bleeding and/or pericardial tamponade. One patient required aortic root replacement 2 days after surgery because of persistent AI. One patient required re-exploration of the aortic root because of acute thrombosis of both coronary artery orifices with large white filamentous strands from a transient undiagnosed hematologic disorder associated with profound thrombocytopenia. One patient required laparotomy to repair a liver rupture caused by cardiac resuscitation. In addition, 4 patients experienced a perioperative myocardial infarction, 2 developed renal failure, 2 experienced a stroke, and 2 experienced a transient ischemic attack. Seventy-six patients developed new transient atrial fibrillation postoperatively. Four patients (3 reimplantation and 1 remodeling) required permanent transvenous pacemaker implantation because of complete heart block in 2 patients and sick sinus syndrome in 2. One patient developed sternal infection. One half of all the patients required blood product transfusion.

\section{Late Mortality}

A total of 39 late deaths occurred: 14 cardiovascular related (1 stroke, 5 sudden death, 2 myocardial infarction, and 6 related to complications of aortic dissection) and 25 non-cardiovascular-related deaths. Figure 1 shows the patient survival compared with that of the general population and matched for age and gender. The patients who had undergone AVS surgery had lower survival rates than the general population during the first 2 decades of follow-up $(P=.001)$. The survival at various intervals is listed in Table 3. The possible predictors of mortality on univariable analysis are listed in Table 4. Multivariable analysis disclosed that age by 5-year increment (hazard ratio [HR], 1.41; 95\% confidence interval [CI], 1.24-1.61; 
TABLE 1. Clinical characteristics of all patients and subgroups stratified by type of aortic valve sparing

\begin{tabular}{|c|c|c|c|c|}
\hline Variable & All patients & Reimplantation & Remodeling & $P$ value \\
\hline Patients (n) & 371 & 296 & 75 & .000 \\
\hline Age (y) & & & & .008 \\
\hline Mean \pm SD & $47.4 \pm 15.1$ & $46.4 \pm 15.0$ & $51.5 \pm 14.6$ & \\
\hline Range & $11-79$ & $11-79$ & $21-77$ & \\
\hline Male gender & $290(78.1)$ & $231(78)$ & $59(78.6)$ & 1.00 \\
\hline \multicolumn{5}{|l|}{ Clinical presentation } \\
\hline Chest pain & $26(7)$ & $19(6.4)$ & $7(9.3)$ & .41 \\
\hline Heart failure & $37(10)$ & $22(7.4)$ & $15(20)$ & .004 \\
\hline Shock & $4(1)$ & $2(0.6)$ & $2(2.7)$ & .19 \\
\hline Syncope & $8(2.1)$ & $7(2.4)$ & $1(1.3)$ & 1.00 \\
\hline \multicolumn{5}{|l|}{ Preoperative ECG findings } \\
\hline Sinus rhythm & $353(95.6)$ & $286(97.2)$ & $67(89.3)$ & .04 \\
\hline Atrial fibrillation & $14(3.8)$ & $7(2.4)$ & $7(9.3)$ & .01 \\
\hline Heart block or pacemaker & $2(0.5)$ & $1(0.3)$ & $1(1.3)$ & .37 \\
\hline Urgent or emergency surgery & $35(9.4)$ & $25(8.4)$ & $10(13.3)$ & .18 \\
\hline Previous cardiac surgery & $19(5.1)$ & $14(4.8)$ & $5(6.7)$ & .56 \\
\hline NYHA functional class & & & & .28 \\
\hline I & $212(57.1)$ & $175(59.1)$ & $37(49.3)$ & \\
\hline II & $96(25.8)$ & $76(25.6)$ & $20(26.7)$ & \\
\hline III & $27(7.2)$ & $19(6.4)$ & $8(10.7)$ & \\
\hline IV & $36(9.7)$ & $26(8.7)$ & $10(13.3)$ & \\
\hline $\operatorname{LVEF}(\%)$ & & & & .01 \\
\hline$\geq 60$ & $263(71.2)$ & $215(72.8)$ & $48(64.8)$ & \\
\hline $40-59$ & $80(21.6)$ & $59(20)$ & $21(28.3)$ & \\
\hline $20-39$ & $24(6.5)$ & $21(7.1)$ & $3(4)$ & \\
\hline$\leq 20$ & $2(0.5)$ & 0 & $2(2.7)$ & \\
\hline \multicolumn{5}{|l|}{ Associated disease } \\
\hline Marfan syndrome & $131(35.5)$ & $108(36.7)$ & $23(30.7)$ & .35 \\
\hline Type A dissection & & & & .008 \\
\hline Acute & $28(7.2)$ & $18(6.1)$ & $10(13.3)$ & \\
\hline Chronic & $17(4.3)$ & $10(3.4)$ & $7(9.3)$ & \\
\hline Diabetes mellitus & $11(3.0)$ & $9(3.1)$ & $2(2.7)$ & 1.00 \\
\hline Hypertension & $145(39.3)$ & $115(39.1)$ & $30(40)$ & .90 \\
\hline Hyperlipidemia & $75(20.3)$ & $62(21.1)$ & $13(17.3)$ & .52 \\
\hline Smoking & $160(43.8)$ & $127(43.6)$ & $33(44.6)$ & .90 \\
\hline $\mathrm{COPD}\left(\mathrm{FEV}_{1}<1.0\right)$ & $12(3.3)$ & $7(2.4)$ & $5(6.7)$ & .07 \\
\hline Stroke or TIA & $10(2.7)$ & $7(2.4)$ & $3(4.0)$ & .43 \\
\hline PVD & $5(1.4)$ & $5(1.7)$ & 0 & .59 \\
\hline Renal failure (dialysis) & $4(1.1)$ & $4(1.4)$ & 0 & .59 \\
\hline \multicolumn{5}{|l|}{ Preoperative findings } \\
\hline Aortic root diameter (mm) & $55 \pm 4$ & $55 \pm 5$ & $56 \pm 5$ & .81 \\
\hline Bicuspid aortic valve & $34(9.2)$ & $32(10.8)$ & $2(2.6)$ & .03 \\
\hline Aortic regurgitation & & & & .35 \\
\hline None or trace & $104(30.9)$ & $86(32.3)$ & $18(25.7)$ & \\
\hline Mild & $66(19.6)$ & $53(19.9)$ & $13(18.5)$ & \\
\hline Moderate & $89(26.4)$ & $64(24)$ & $25(35.7)$ & \\
\hline Severe & $77(22.9)$ & $63(23.6)$ & $14(20)$ & \\
\hline Mitral regurgitation & $31(8.4)$ & $25(8.5)$ & $6(8)$ & .96 \\
\hline Tricuspid regurgitation & 1 & 1 & 0 & 1.00 \\
\hline PV dysfunction & 2 & 2 & 0 & 1.00 \\
\hline Atrial septal defect & $15(4.0)$ & $15(5.1)$ & 0 & .05 \\
\hline Ventricular septal defect & 3 & 3 & 0 & 1.00 \\
\hline Coronary artery disease & $38(10.2)$ & $29(9.8)$ & $9(12)$ & .68 \\
\hline
\end{tabular}

Data presented as mean \pm standard deviation or $\mathrm{n}(\%) . E C G$, Electrocardiographic; $N Y H A$, New York Heart Association; $L V E F$, left ventricular ejection fraction; $C O P D$, chronic obstructive pulmonary disease; $F E V_{l}$, forced expiratory volume in 1 second; $P V D$, peripheral vascular arterial disease; $P V$, pulmonary valve; $S D$, standard deviation; $T I A$, transient ischemic attack. 
TABLE 2. Operative data

\begin{tabular}{|c|c|c|c|}
\hline Variable & Reimplantation & Remodeling & $\begin{array}{c}P \\
\text { value }\end{array}$ \\
\hline Dacron graft diameter (mm) & $31 \pm 4$ & $28 \pm 4$ & $<.001$ \\
\hline Creation of neoaortic sinus & 138 (46.6) & $75(100)$ & $<.001$ \\
\hline Cusps shortened by plication (n) & & & .02 \\
\hline 1 & $55(18.7)$ & $21(28)$ & \\
\hline 2 & $41(14)$ & $2(2.7)$ & \\
\hline 3 & $15(5.1)$ & $2(2.7)$ & \\
\hline $\begin{array}{l}\text { Cusps reinforced with } \\
\text { Gore-Tex (n) }\end{array}$ & & & .78 \\
\hline 1 & $62(21.1)$ & $16(21.3)$ & \\
\hline 2 & $7(2.4)$ & $3(4)$ & \\
\hline 3 & $2(0.7)$ & 0 & \\
\hline Aortic arch replacement & $39(13.3)$ & $21(28)$ & .004 \\
\hline Coronary artery bypass grafting & $29(9.8)$ & $9(12)$ & .68 \\
\hline $\begin{array}{l}\text { Patch angioplasty of left } \\
\text { main artery }\end{array}$ & $5(1.7)$ & 0 & .59 \\
\hline Mitral valve repair & $25(8.4)$ & $6(8)$ & 1.00 \\
\hline Mitral valve replacement & $1(0.3)$ & 0 & 1.00 \\
\hline Tricuspid valve repair & $1(0.3)$ & 0 & 1.00 \\
\hline Pulmonary valve replacement & $2(0.7)$ & 0 & 1.00 \\
\hline Repair of congenital heart defects & $18(6.1)$ & 0 & .03 \\
\hline Maze procedure & $4(1.4)$ & 0 & .59 \\
\hline $\begin{array}{l}\text { Repair of abdominal aortic } \\
\text { aneurysm }\end{array}$ & $1(03)$ & 0 & 1.00 \\
\hline $\begin{array}{l}\text { Cardiopulmonary bypass } \\
\text { time }(\mathrm{min})\end{array}$ & $141 \pm 32$ & $126 \pm 32$ & .001 \\
\hline Aortic crossclamp time (min) & $117 \pm 27$ & $102 \pm 24$ & $<.001$ \\
\hline Circulatory arrest & $45(15.3)$ & $21(28)$ & .02 \\
\hline Body surface area $\left(\mathrm{m}^{2}\right)$ & $2.04 \pm 0.26$ & $2.05 \pm 0.27$ & .69 \\
\hline Body mass index $\left(\mathrm{kg} / \mathrm{m}^{2}\right)$ & $26.5 \pm 4.9$ & $27.1 \pm 5.0$ & .37 \\
\hline
\end{tabular}

Data presented as mean \pm standard deviation or $\mathrm{n}(\%)$.

$P<.001)$, type A aortic dissection (HR, 2.18; 95\% CI, 1.11-4.28; $P=.02$ ), preoperative moderate or severe AI (HR, 2.18; 95\% CI, 1.07-4.47; $P=.03$ ), and lower left ventricular ejection fraction per grade (HR, 1.84; 95\% CI, 1.23-2.75; $P=.003$ ) were independent predictors of mortality.

\section{Reoperations}

Ten patients required reoperation on the aortic valve (reimplantation in 5 and remodeling in 5). The indications for repeat aortic valve surgery were AI in 8 patients and infective endocarditis with aortic root abscess in 2 (1 reimplantation; 1 remodeling). The aortic valve was repaired again in 1 patient and replaced in 9 patients ( 3 aortic valve replacement; 6 aortic root repeat replacement). Of the 8 reoperations for AI, 7 were performed by us. The mechanism of AI in 4 patients who underwent reimplantation of the aortic root was prolapse due to detachment of 1 cusp from its commissure (this valve was repaired again by resuspension of the cusp with Gore-Tex suture), and cusp prolapse with degenerative changes in the other 3. The mechanism of AI in the 4 patients who had remodeling of

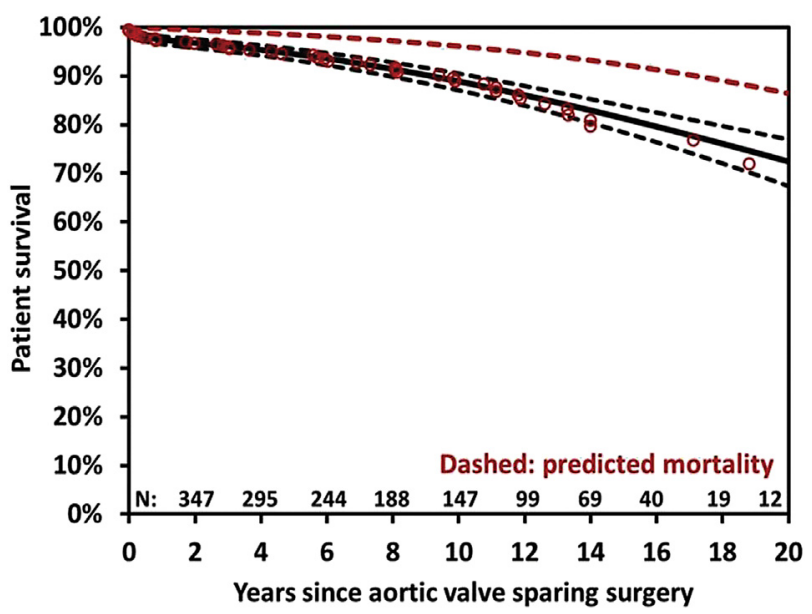

FIGURE 1. Patient survival compared with the general population and matched for age and gender.

the aortic root was cusp prolapse due to dilatation of the aortic annulus (from $28 \pm 3 \mathrm{~mm}$ early postoperatively to $35 \pm 4 \mathrm{~mm}$ before reoperation). Remodeling of the aortic root was marginally associated with a greater risk of reoperation on univariable analysis $(\mathrm{HR}, 3.37$; 95\% CI, $0.88-12.82 ; P=.07)$. Figure 2 shows the freedom from reoperation on the aortic valve in all patients and in the 2 subgroups. The rates at various intervals are listed in Table 3. In addition to aortic valve reoperations, 2 patients required mitral valve repair, 1 patient, replacement of the transverse arch using the elephant trunk technique, and 1 patient, replacement of the entire thoracic and abdominal aorta. No operative deaths occurred among the patients who required reoperation, but 1 patient became paraplegic.

\section{Echocardiographic Studies}

Eighteen patients developed moderate or severe AI during the follow-up period (12 reimplantation; 6 remodeling). Although remodeling of the aortic root, preoperative AI, bicuspid aortic valve, and preoperative mitral regurgitation were associated with a greater risk of AI on univariable analysis, no predictor of postoperative AI was found on multivariable analysis. No patient had more than mild AI on the echocardiogram taken before discharge from the hospital, and this degree of early AI was not a factor in the development of late AI on either univariable or multivariable analysis. Similarly, the time of the operation (early vs late experience) was not a factor in the development of AI. Figure 3 shows the freedom from moderate and severe $\mathrm{AI}$ in all patients and stratified by reimplantation and remodeling. The rates at the various intervals are listed in Table 3. In addition to AI, 24 patients developed new moderate or severe mitral insufficiency. The freedom from mitral insufficiency at various intervals is also listed in Table 3. 
TABLE 3. Freedom from morbid events at various intervals

\begin{tabular}{lcccrc}
\hline & \multicolumn{4}{c}{ Follow-up point $(\mathbf{y})$} \\
\cline { 2 - 6 } \multicolumn{1}{c}{ Freedom from } & $\mathbf{1}$ & $\mathbf{5}$ & $\mathbf{1 0}$ & $\mathbf{1 5}$ & $\mathbf{1 8}$ \\
\hline Mortality & $97.3 \pm 0.8$ & $94.6 \pm 1.2$ & $89.0 \pm 2.0$ & $79.7 \pm 3.4$ & $76.8 \pm 4.3$ \\
Reoperation* & $99.7 \pm 0.3$ & $99.7 \pm 0.3$ & $97.0 \pm 1.3$ & $94.8 \pm 2.0$ & $94.8 \pm 2.0$ \\
Aortic insufficiency $\dagger$ & $99.7 \pm 0.3$ & $99.6 \pm 0.4$ & $93.2 \pm 2.0$ & $90.7 \pm 2.6$ & $78.0 \pm 4.8$ \\
Mitral insufficiency $\dagger$ & 100 & $99.2 \pm 0.6$ & $92.8 \pm 2.1$ & $88.8 \pm 3.5$ & $88.8 \pm 3.5$ \\
Thromboembolism $§$ & $99.5 \pm 0.4$ & $96.6 \pm 1.0$ & $94.1 \pm 1.5$ & $92.2 \pm 2.4$ & $90.1 \pm 3.2$ \\
Valve-related event $\mid$ & $98.1 \pm 0.6$ & $95.5 \pm 1.1$ & $91.2 \pm 2.4$ & $85.5 \pm 3.8$ & $79.4 \pm 4.6$ \\
\hline
\end{tabular}

Data presented as mean percentage \pm standard deviation. *Reoperation on the aortic valve. $\dagger$ Aortic insufficiency grade moderate or severe. $\ddagger$ Mitral insufficiency grade moderate or severe. §Transient ischemic attack or stroke. ||Valve-related death, reoperation, aortic insufficiency, thromboembolism, hemorrhage, and endocarditis.

\section{Other Late Adverse Events}

Four patients developed infective endocarditis $(2$ mitral, treated with antibiotics alone; and 2 aortic, treated with antibiotics and surgery). Six patients experienced a stroke and 19 transient ischemic attacks. The freedom from thromboembolic events at various intervals is listed in Table 3. At the latest follow-up point, 39 patients were taking an oral anticoagulant because of atrial fibrillation, pacemaker implantation, or a previous thromboembolic event, and 8 had experienced anticoagulation-related hemorrhage. The freedom from any valve-related adverse event is listed in Table 3. Two patients experienced a myocardial infarction. Ten patients required permanent transvenous pacemaker implantation because of heart block or sick sinus syndrome (7 reimplantation; 3 remodeling).

\section{Functional Class}

At the most recent follow-up visit, 319 patients were alive and had their native aortic valve. Of these patients,

TABLE 4. Factors associated with increased hazard of mortality on univariable analysis $(P<.05)$

\begin{tabular}{|c|c|c|c|}
\hline Potential predictor & HR & $\mathbf{9 5} \% \mathrm{CI}$ & $P$ value \\
\hline Older age at surgery (per yr) & 1.074 & $1.049-1.100$ & $<.001$ \\
\hline Higher NYHA functional class (per level) & 1.650 & $1.292-2.108$ & $<.001$ \\
\hline Lower LVEF (per level) & 2.336 & $1.659-3.289$ & $<.001$ \\
\hline Preoperative hypertension & 3.693 & $1.960-6.958$ & $<.001$ \\
\hline Symptoms of heart failure & 4.663 & $2.501-8.695$ & $<.001$ \\
\hline Serum creatinine $>50 \mu \mathrm{mol} / \mathrm{L}$ & 1.172 & $1.087-1.263$ & $<.001$ \\
\hline Coronary artery disease (per vessel) & 1.762 & $1.304-2.383$ & $<.001$ \\
\hline Longer CPB time (per $30 \mathrm{~min}$ ) & 1.628 & $1.316-2.014$ & $<.001$ \\
\hline $\begin{array}{l}\text { Longer aortic crossclamp time } \\
\quad \text { (per } 30 \mathrm{~min} \text { ) }\end{array}$ & 1.732 & $1.300-2.308$ & $<.001$ \\
\hline Circulatory arrest & 3.385 & $1.850-6.192$ & $<.001$ \\
\hline Aortic arch replacement & 3.071 & $1.668-5.654$ & $<.001$ \\
\hline Type A aortic dissection & 2.066 & $1.379-3.093$ & $<.001$ \\
\hline Preoperative moderate or severe AI & 3.070 & $1.492-6.317$ & .002 \\
\hline Hyperlipidemia & 2.564 & $1.313-5.009$ & .006 \\
\hline Marfan syndrome & 0.360 & $0.171-0.755$ & .007 \\
\hline Any previous cardiac surgery & 3.612 & $1.262-10.33$ & .02 \\
\hline
\end{tabular}

$80 \%$ were in New York Heart Association class I, $15 \%$ in class II, and $5 \%$ in class III.

\section{DISCUSSION}

The results of the present study have provided additional information on the clinical and echocardiographic outcomes after AVS operations to treat patients with aortic root aneurysms or ascending aortic aneurysms and dilated
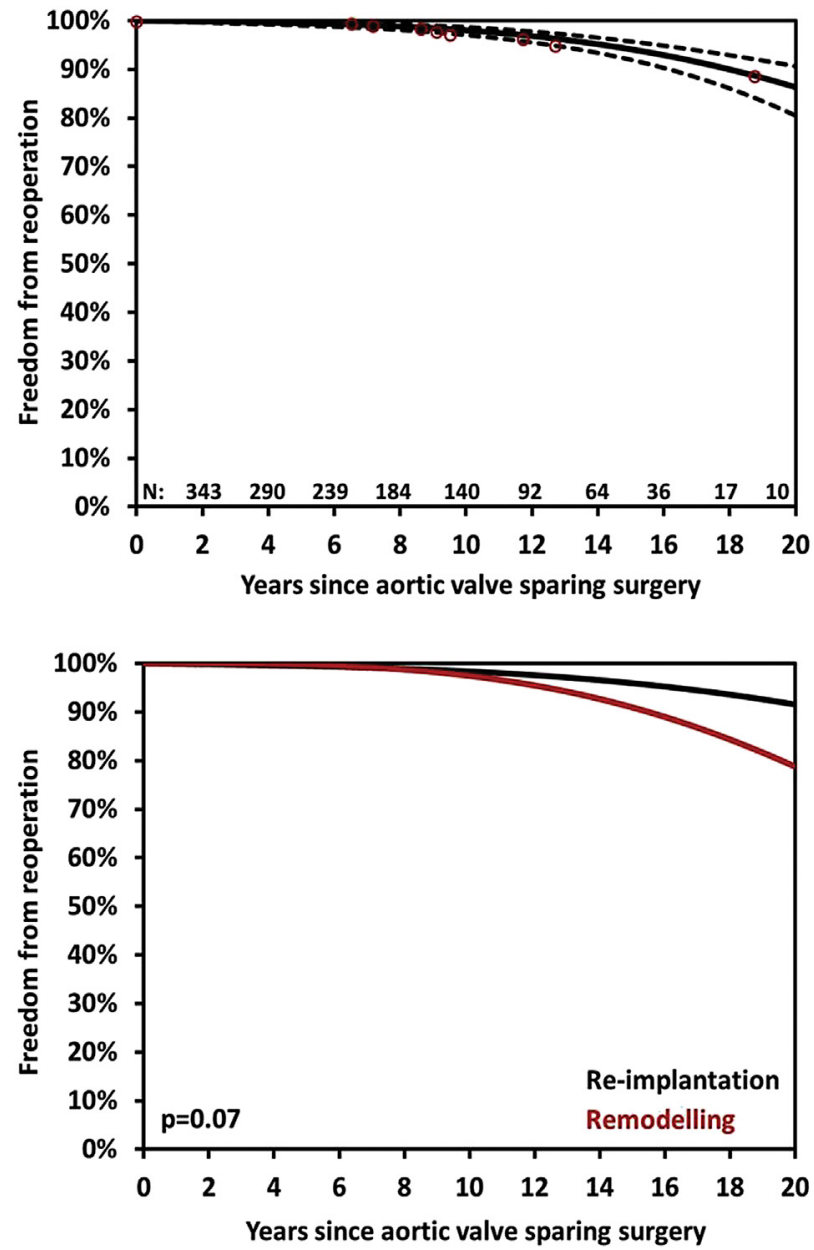

FIGURE 2. Freedom from reoperation on the aortic valve, upper, for all patients and, lower, after reimplantation and remodeling procedures. 

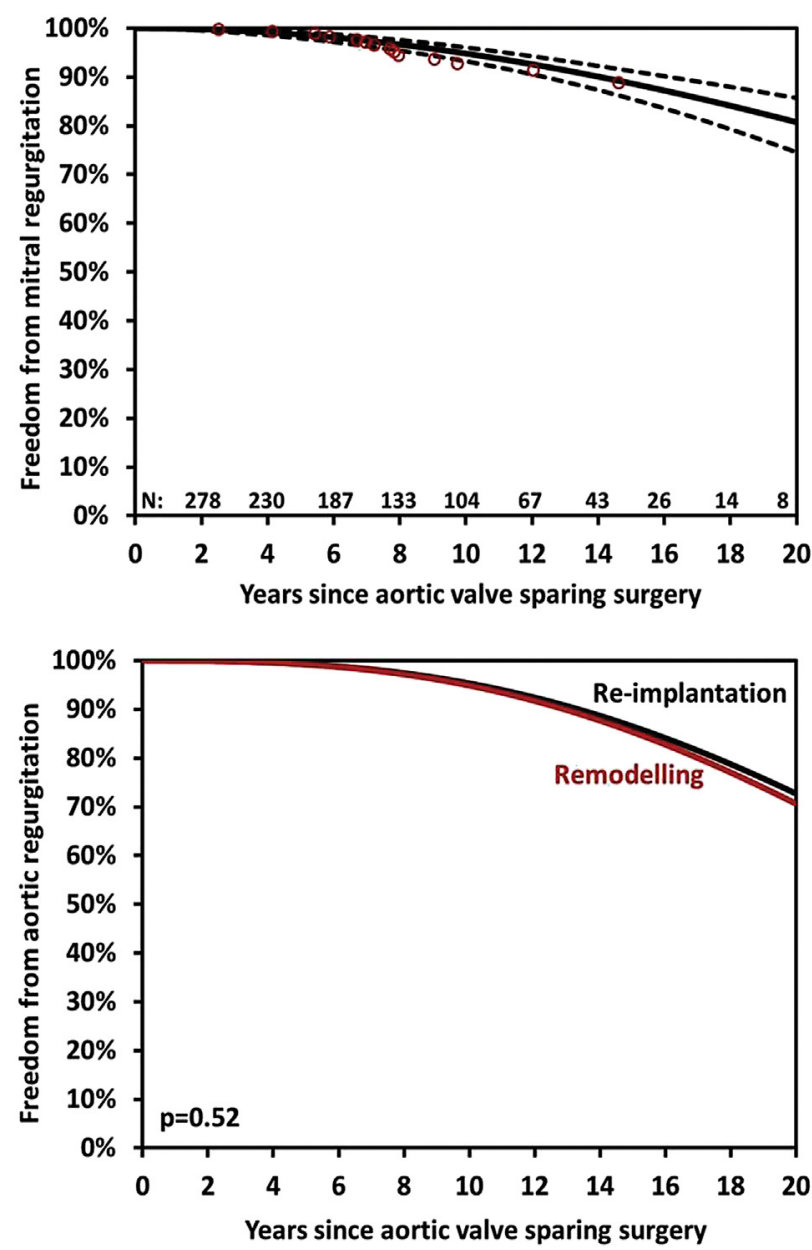

FIGURE 3. Freedom from moderate or severe aortic insufficiency, upper, in all patients and, lower, after reimplantation and remodeling procedures.

aortic sinuses with or without AI. When these operations were first developed, we did not distinguish the aortic root aneurysms, such as those in patients with Marfan syndrome, from the aortic sinus dilatation associated with ascending aortic aneurysms. ${ }^{2,6}$ Patients with aortic root aneurysm will usually be in their second, third, or fourth decade of life, and the aneurysms will frequently be associated with an inherited disorder such as Marfan syndrome, Loyes-Dietz syndrome, familial aneurysms, or osteoarthritis aneurysm syndrome when they come to surgical attention. The aneurysm will almost always have begun in the aortic sinuses and expanded proximally and distally into the aortic annulus and sinotubular junction. Patients with an ascending aortic aneurysm and dilated aortic sinuses will usually be in their fifth, sixth, and seventh decades of life, and the aneurysm will have begun in the ascending aorta and expanded proximally into the sinotubular junction and aortic sinuses (but seldom into the aortic annulus) and distally into the aortic arch. The dilatation of the aortic sinuses will often be asymmetric, and the noncoronary aortic sinus will be the first to dilate, followed by the right and left. Bicuspid aortic valve disease is a different entity. When the valve becomes incompetent, it will frequently be associated with dilatation of the aortic annulus. Patients with inherited aortic root aneurysm could also have a bicuspid aortic valve. We believe this heterogeneity of pathologic entities must be accounted for when selecting the type of AVS to treat the aortic sinus aneurysm.

AVS operations were developed to restore the anatomy and function of the aortic root. Given the anatomy of the aortic annulus and aortic cusps, the areas of the aortic cusps must be much larger than the area of the aortic annulus. Thus, as long as no mismatch is present between the size of the aortic cusps and the size of the aortic annulus, replacement of the aneurysmal aortic sinuses with adjustment of the diameter of the sinotubular junction and correction of any cusp prolapse will re-establish the normal aortic valve function in patients with ascending aortic aneurysms and dilated aortic sinuses. Therefore, remodeling of the aortic root is ideally suited for these patients, and evidence has shown that this procedure will be very durable in such circumstances. ${ }^{11,15}$ No patient in our series who had undergone remodeling of the aortic root required reoperation or developed recurrent $\mathrm{AI}$, if the patients with Marfan syndrome were excluded. However, patients with genetic aortic root aneurysms and patients with incompetent bicuspid aortic valves will often have a dilated aortic annulus, and remodeling of the aortic root in this subset has resulted in suboptimal long-term results. ${ }^{16-18}$ Reimplantation of the aortic valve is ideally suited for patients with a dilated aortic annulus. This procedure reduces the diameter and reshapes the aortic annulus by fixing it into the cylindrical Dacron graft but places the aortic cusps into a noncompliant structure. The selection of the graft size for the reimplantation procedure is crucial and difficult. Although the height of the aortic cusps, length of their free margins, height of the commissures, and diameter of the aortic annulus and/or sinotubular junction have been used to estimate the diameter of the graft, no single measurement will give the correct diameter, because the components of the aortic root will often be abnormal in patients with aortic root aneurysm. ${ }^{2,13,14,19,20}$ We believe that the height of the cusp is the single most important parameter for estimating the graft diameter. The radius of the aortic annulus at the level of the nadir of the cusps should be approximately two thirds of the height of cusps. Because the graft lies on the outside of the aortic annulus, 3 to $4 \mathrm{~mm}$ should be added to the estimated internal diameter to compensate for the thickness of the aortic annulus. ${ }^{2}$

Another controversial issue with AVS operations is whether the creation of neoaortic sinuses is important for valve function. Undoubtedly, placing the cusps inside a rigid, noncompliant structure such as a cylindrical Dacron 
graft will increase the velocity of the opening and closure of the cusps, alter the bending characteristics of the cusps during the cardiac cycle, and probably increase the mechanical stress on the cusps. ${ }^{21-23}$ We have never used the Valsalva graft, ${ }^{23}$ because the aortic annulus will be placed inside a spherical structure instead of a cylindrical structure, such as nature created the semilunar valves. We have created neoaortic sinuses by placing darts in a tubular Dacron graft in the spaces between the commissures, ${ }^{13,14}$ but we have been unable to show that artificially created sinuses improve the durability of the AVS procedure. Thus, we have only plicated the spaces in between commissures if, after implanting the aortic valve into a tubular Dacron graft, we have found that the intercommissural distance of a given cusp prevents the cusp from coapting with others. Thus, plication of $\geq 1$ intercommissural spaces will be used to optimize cusp coaptation rather than to create a neoaortic sinus.

Survival after the AVS procedure in our series was less than that of the general population matched for age and gender. This was not surprising, given the extensiveness of the associated disorders that many of our patients had.

Only 8 patients have required reoperation for AI. Statistical modeling is difficult with such a small number of adverse events to determine the causes of failure. The same can be said about the type of AVS. Experience from multiple centers has shown that certain technical aspects of the AVS procedure play an important role in postoperative aortic valve function. With both techniques of AVS, uncorrected cusp prolapse has probably been the most common cause of early valve failure. ${ }^{3,24,25}$ In addition, the level of coaptation of the aortic cusps in relation to the aortic annulus appears to be very important, in particular, after the reimplantation procedure. ${ }^{25,26}$ Just as in the normal aortic root, the cusps should coapt within the aortic root, with several millimeters above the nadir of the aortic annulus, regardless of the type of AVS procedure performed. The coaptation length and coaptation height are determined by a complex relationship among the diameter of the graft used, length of the free margin of the cusp, height of the cusp, height of the commissures, and intercommissural distances. We believe that the diameter of the graft used for reconstruction of the aortic root is crucial with both techniques. Once the aortic annulus and sinotubular junction have been stabilized with a Dacron graft, careful assessment of the cusps and the level at which they coapt in relation to the aortic annulus should be performed and corrected if needed. The coaptation level can be raised by shortening the free margin of the cusp, either by plication along the nodule of Arantius or with a double-layer of a fine Gore-Tex suture along the free margin from commissure to commissure. ${ }^{4,5}$ If a cusp lies too high and barely touches the other 2 , a reduction of the intercommissural distance will lower the level of the free margin. Thus, just as with any valve reconstructive procedure, a sound knowledge of the functional anatomy and how the various components interplay is indispensable for a good functional result. We only began to collect information regarding the cusps' coaptation height and coaptation length after the findings reported by Kunihara and colleagues. ${ }^{25}$ Because our data set did not contain this variable, it is possible that an inadequate repair could have contributed to the development of late AI. Finally, we found an unexpectedly high proportion of new moderate or severe mitral insufficiency in our patients during follow-up, regardless of the type of AVS surgery used. This finding underscores the importance of continued echocardiographic surveillance in these patients.

\section{Study Limitations}

Although our experience with AVS operations spanned more than one quarter of century, we had only 43 patients at risk after 15 years and 11 after 20 years. Thus, the outcomes after 15 years might not be statistically valid, despite the type of analysis used. Because a large number of late echocardiographic studies were performed and interpreted outside of our hospital, one could question the validity of the results. Also, we might have underestimated the severity of the aortic valve dysfunction. Finally, because we did not have echocardiographic data such as the cusp coaptation height and coaptation length, we could have missed factors predictive of recurrent AI.

\section{CONCLUSIONS}

AVS operations have become a part of the surgical armamentarium for treating patients with aortic root aneurysms and ascending aorta aneurysms with dilated aortic sinuses. We believe that reimplantation of the aortic valve is ideal for younger patients with inherited aortic root aneurysms and that remodeling of the aortic root is ideal for older patients with ascending aortic aneurysms, dilated aortic sinuses, and a normal aortic annulus. The long-term results have continued to be excellent; however, valve function appeared to deteriorate slowly during the second decade of follow-up. AVS operations will be feasible for most, if not all, patients with normal or mildly stretched aortic cusps. Recent knowledge of the importance of cusp configuration after reconstruction of the aortic root should enhance the durability of AVS operations. ${ }^{25}$

\section{References}

1. David TE. The aortic valve-sparing operation. J Thorac Cardiovasc Surg. 2011; 141:613-5.

2. David TE, Feindel CM. An aortic valve sparing operation for patients with aortic incompetence and aneurysm of the ascending aorta. J Thorac Cardiovasc Surg. 1992; 103:617-22.

3. Langer F, Graeter T, Nikoloudakis N, Aicher D, Wendler O, Schäfers HJ. Valve-preserving aortic replacement: does the additional repair of leaflet prolapse adversely affect the results? J Thorac Cardiovasc Surg. 2001;122:270-7. 
4. de Kerchove L, Glineur D, Poncelet A, Boodhwani M, Rubay J, Dhoore W, et al. Repair of aortic leaflet prolapse: a ten-year experience. Eur J Cardiothorac Surg. 2008;34:785-91.

5. David TE, Armstrong S. Aortic cusp repair with Gore-Tex sutures during aortic valve-sparing operations. J Thorac Cardiovasc Surg. 2010;139:1340-2.

6. Sarsam MA, Yacoub M. Remodeling of the aortic valve annulus. J Thorac Cardiovasc Surg. 1993;105:435-8.

7. David TE, David TE, Feindel CM, Bos J. Repair of the aortic valve in patients with aortic insufficiency and aortic root aneurysm. J Thorac Cardiovasc Surg. 1995; 109:345-52.

8. David TE. Remodeling of the aortic root and preservation of the native aortic valve. Op Tech Cardiac Thorac Surg. 1996;1:44-56.

9. De Paulis R, De Matteis GM, Nardi P, Scaffa R, Buratta MM, Chiarello L. Opening and closing characteristics of the aortic valve after valve-sparing procedures using a new aortic root conduit. Ann Thorac Surg. 2001;72:487-94.

10. Miller DC. Valve-sparing aortic root replacement in patients with the Marfan syndrome. J Thorac Cardiovasc Surg. 2003;125:773-8.

11. Urbanski PP, Zhan X, Hijazi H, Zacher M, Diegeler A. Valve-sparing aortic root repair without down-sizing of the annulus. J Thorac Cardiovasc Surg. 2012;143: 294-302.

12. Lansac E, Di Centa I, Raoux F, Bulman-Fleming N, Ranga A, Abed A, et al. An expansible aortic ring for a physiological approach to conservative aortic valve surgery. J Thorac Cardiovasc Surg. 2009;138:718-24.

13. David TE. How I do aortic valve sparing operations to treat aortic root aneurysm. J Card Surg. 2011;26:92-9.

14. David TE, Maganti M, Armstrong S. Aortic root aneurysm: principles of repair and long-term follow-up. J Thorac Cardiovasc Surg. 2010;140:14-9.

15. Aicher D, Langer F, Lausberg H, Bierbach B, Schäfers HJ. Aortic root remodeling: ten-year experience with 274 patients. J Thorac Cardiovasc Surg. 2007;134:909-15.

16. Benedetto U, Melina G, Takkenberg JJ, Roscitano A, Angelini E, Sinatra R. Surgical management of aortic root disease in Marfan syndrome: a systematic review and meta-analysis. Heart. 2011;97:955-8.

17. de Oliveira NC, David TE, Ivanov J, Armstrong S, Eriksson MJ, Rakowski H, et al. Results of surgery for aortic root aneurysm in patients with Marfan syndrome. J Thorac Cardiovasc Surg. 2003;125:789-96.

18. de Kerchove L, Boodhwani M, Glineur D, Vandyck M, Vanoverschelde JL, Noirhomme P, et al. Valve sparing-root replacement with the reimplantation technique to increase the durability of bicuspid aortic valve repair. $J$ Thorac Cardiovasc Surg. 2011;142:1430-8.

19. de Kerchove L, Boodhwani M, Glineur D, Noirhomme P, El Khoury G. A new simple and objective method for graft sizing in valve-sparing root replacement using the reimplantation technique. Ann Thorac Surg. 2011;92:749-51.

20. Schäfers HJ, Schmied W, Marom G, Aicher D. Cusp height in aortic valves. J Thorac Cardiovasc Surg. 2013;146:269-74.

21. Leyh RG, Schmidtke C, Sievers HH, Yacoub MH. Opening and closing characteristics of the aortic valve after different types of valve-preserving surgery. Circulation. 1999;100:2152-60.

22. Aybek T, Sotiriou M, Wöhleke T, et al. Valve opening and closing dynamics after different aortic valve-sparing operations. J Heart Valve Dis. 2005;14:114-20.

23. De Paulis R, De Matteis GM, Nardi P, Scaffa R, Colella DF, Bassano C, et al. One-year appraisal of a new aortic root conduit with sinuses of Valsalva. J Thorac Cardiovasc Surg. 2002;123:33-9.

24. Oka T, Okita Y, Matsumori M, Okada K, Minami H, Munakata H, et al. Aortic regurgitation after valve-sparing aortic root replacement: modes of failure. Ann Thorac Surg. 2011;92:1639-44.

25. Kunihara T, Aicher D, Rodionycheva S, Groesdonk HV, Langer F, Sata F, et al. Preoperative aortic root geometry and postoperative cusp configuration primarily determine long-term outcome after valve-preserving aortic root repair. J Thorac Cardiovasc Surg. 2012;143:1389-95.

26. Pethig K, Milz A, Hagl C, Harringer W, Haverich A. Aortic valve reimplantation in ascending aortic aneurysm: risk factors for early valve failure. Ann Thorac Surg. 2002;73:29-33.

\section{Discussion}

Dr Hans-Joachim Schäfers (Homburg/Saar, Germany). It is a privilege for me to discuss this important contribution from Dr David and his coworkers, Dr David being a true pioneer in valve-preserving aortic replacement. You have demonstrated the durability of preservation of the aortic valve reaching $\leq 25$ years, although only 43 patients were beyond 15 years at this point. Nevertheless, excellent results.

An interesting finding in your present review was that in patients without Marfan syndrome, remodeling and reimplantation actually achieved similar results. Interesting, of course, and we always have to learn from our failures, is the question, what happened to the aortic valve in the 8 patients in whom you reoperated electively for aortic regurgitation? In this context, if we have learned something, and I have also learned from you, it is important to achieve a normal aortic valve configuration at the end of the operation, with cusp plication or correction of cusp prolapse an integral part of the procedure.

My question to you is, has there been a learning curve for you? In other words, have you increased the percentage of cusp manipulations over time?

Finally, in terms of selecting valve preservation, have there been morphologic findings at the operation that would now prompt you to abort the repair and perform replacement (ie, extensive fenestrations, cusp retractions, or calcification)?

Again, my congratulations for this important pioneering work and an excellent presentation.

Dr David (Toronto, Ontario, Canada). Thank you, Dr Schäfers. Your contributions to this area are also commendable. To be quite honest, we learned from you the importance of the coaptation height and coaptation area. However, before that, we did not enter these variables into our database; thus, we could not determine whether these patients had had an inadequate repair. To study echocardiograms from 20 years ago would be almost impossible, because in those days, they were only on video, and most were destroyed. So, I do not know the answer for that.

Reviewing the operative reports of those patients in whom the aortic valve reoperation was done for AI, all the patients had cusp prolapse, except for 1 , in whom the cusps were calcified and had developed a mixed lesion. I do believe that by giving more attention to the technical aspects that you emphasized on the proper coaptation and leaflet geometry at the end of the operation, we might improve on these results.

Before I embarked on this type of operation, I had quite extensive experience with stentless valves. Thus, unlike most surgeons, I did not experience a learning curve. From the beginning, we knew what was required to make a stentless valve competent, and we might have abolished the learning curve with aortic valve sparing. What we did not know, however, was the pathologic features of the aortic annulus. I had no idea 25 years ago that a larger aortic annulus was a sign of a more extensive connective tissue disorder.

The selection of patients is crucial, of course. More than one half of our patients had either leaflet fenestration or leaflet prolapse. Repairing them did not cause recurrent AI. Thus, the outcomes 15 and 20 years later appeared to be unaffected by leaflet repair at surgery. I believe those patients should be included as candidates for aortic valve repair.

Calcification or even sclerosis is different. I should add an observation made in my operative notes. I described whether the cusps were elastic or sclerotic. Elastic cusps provided the best long-term outcomes. I think they are adaptable to a rigid structure, 
particularly in the reimplantation technique. That is why younger patients will do better than older ones with reimplantation.

These 2 operations are not competitive; each one has a place, and, in my opinion, older patients, older than 40 or 50 years, should undergo remodeling if the annulus is normal, with reimplantation reserved for genetic aneurysms.

Dr Lars G. Svensson (Cleveland, Ohio). Tirone, once again, a great presentation, and as I have said before to you, thank you for teaching me this wonderful operation.

We have done some 440 David reimplantations now, and I agree with you entirely that the long-term results have been excellent. We hope to live up to your standards, but valve failure is not an issue. We have had a couple of patients with endocarditis, so that certainly can happen. In your series, just as we have seen also, the risk of dissection is still prevalent in these patients, even if the distal aorta is of normal size. Nearly one half of your 14 cardiovascular deaths were related to dissection. Thus, one of my questions is, what are you doing about monitoring those patients? We have seen patients with a normal descending aorta have a successful David procedure and then come back 1 year later with dissection.

Also, perhaps you could comment on the controversyobviously all of us use $\beta$-blockers in high-risk patients_—regarding the use of losartan after surgery and whether you think that makes any difference.

Dr David. That is a very good point, because the operation does not seem to abolish the risk of dissection beyond the area that has been replaced. I did not give the incidence of dissection, but it remains a problem in patients with genetic aneurysms. Many patients such as yours will have had a successful operation and 2, 3, 5 years later will have developed a type B dissection, particularly the subgroup with Marfan syndrome.

We encourage every young patient to take $\beta$-blockers permanently. Whether they will or not is a different story. However, I do not know of anything we can do to abolish the risk of dissection in patients with connective tissue disorder other than giving losartan or $\beta$-blockers. It would be interesting to know what can be done to prevent this dreadful complication of aortic root aneurysms. 